ORIGINAL ARTICLE

\title{
Evaluation of Mental Disorders along with Cardiovascular Diseases among Adult Patients in Tertiary Care Hospitals in Southern Punjab
}

Nauman Mazhar ${ }^{1}$, Naeem Amjad ${ }^{2 *}$, Ikram ul Haq ${ }^{2}$, Majid Bashir ${ }^{3}$, Syed Naseem Bukhari ${ }^{4}$, Tariq Mehmood Khan ${ }^{4}$

\begin{abstract}
Objective: To determine the prevalence of psychiatric disorders in patients with cardiovascular disease and association between psychiatric disorders and cardiovascular diseases and.

Study Design: Cross Sectional study.

Place and Duration of Study: The study was conducted at cardiac wards of Ch.Pervaiz Elahi Institute of Cardiology, Multan from $27^{\text {th }}$ May to $27^{\text {th }}$ October 2020.

Materials and Methods: 200 patients of age above 25 years, both male and female with diagnosis of cardiovascular diseases were included in the study. Cardiovascular disease patients were evaluated to various psychiatric disorders, including depression, post trauma stress disorder, anxiety, dysthymia, and bipolar disorder, panic disorder with or without agoraphobia, social phobia, and psychosis. Those with comorbid psychiatric and cardiovascular diseases were evaluated for socioeconomic conditions. Education, income, occupation and debt were used as indicators for this evaluation. Collected data were analysed through computer software SPSS 23.

Results: Out of 200, 115 (57.5\%) were male and 85 (42.5\%) were female. Mean age of participants was $42.7 \pm$ 6.7 years. Among them, 94 (47\%) were diagnosed positive for mental illness. 10 (10.6\%; OR: 0.298) were detected for anxiety, 20 (21.2\%; OR, 1.47) for depression, 21 (22.3\%; OR, 1.056) for post trauma stress disorder, 7 (7.4\%; OR, 0.26) for dysthymia, 5 (5.31\%; OR, 0.14) for bipolar disorder, 15 (15.9\%; OR, 1.69) for panic disorder, 6 (6.3\%; OR, 0.75) for social phobia and 10 (10.6; OR 0.36) for psychosis. Majority $46.8 \%$ of diagnosed psychiatric disorders had less than 10 years of schooling, $41.4 \%$ were having monthly income less than 25,000 per month, $42.5 \%$ were skilled, and $58.5 \%$ were indebted.

Conclusion: It is concluded that post trauma stress disorder, depression and panic disorder are significantly correlated with cardiovascular diseases. Further, significant number of patients with comorbid mental and cardiovascular were found to have low educational status and were indebted which makes these two a risk factor in causing cardiac disorders.
\end{abstract}

\section{Key Words: Cardiovascular Diseases, Psychiatric Disorders, Socioeconomic Risk Factors.}

How to cite this: Mazhar N, Amjad N, Haq I, Bashir M, Bukhari SN, Khan TM. Evaluation of Various Mental Disorders along with Cardiovascular Diseases among adult patients in Tertiary Care Hospitals in Southern Punjab. Life and Science. 2022; 3(1): 25-29. doi: http://doi.org/10.37185/LnS.1.1.201

This is an Open Access article distributed under the terms of the Creative Commons Attribution License (http://creativecommons.org/licenses/by/4.0), which permits unrestricted use, distribution, and reproduction in any medium, provided the original work is properly cited.

\footnotetext{
${ }^{1}$ Department of Psychiatry

Services Institute of Medical Sciences (SIMS), Lahore

${ }^{2,3}$ Department of Psychiatry

Shahida Islam Medical and Dental College, Lodhran

${ }^{4}$ Department of Cardiology

Nishtar Medical University and Hospital, Multan

${ }^{5,6}$ Department of Cardiology

Ch. Pervaiz Elahi Institute of Cardiology Multan

Correspondence:

Dr. Naeem Amjad

Department of Psychiatry

Shahida Islam Medical and Dental College, Lodhran

E-mail:drnaeem10@yahoo.com

Funding Source: NIL; Conflict of Interest: NIL

Received: Apr 14, 2021; Revised: Sep 14, 2021

Accepted: Nov 28, 2021
}

\section{Introduction}

Cardiovascular diseases are defined as illnesses related to circulatory system of body. Annually, cardiovascular diseases remain a significant cause of health decline throughout the world and leads to 17.2 million deaths. ${ }^{1}$ Similarly, In Pakistan a study concluded that $17.5 \%$ of studied population was suffering from cardiovascular diseases. ${ }^{2}$ Many risk factor have been associated with cardiovascular diseases, including obesity, high blood cholesterol level, drug abuse, poor diet plan, physical restriction, 
and diabetes. ${ }^{3,4}$ In addition, psychological disorders such as a post traumatic disorders and adjustments disorders, a diagnosis given to one who present chronic depression and anxiety symptoms, have also been associated with cardiovascular diseases. ${ }^{5}$ However, the above association has only been studied in the high income countries, while Pakistan is still unknown to this study area. ${ }^{6}$

Further, Pakistan is one of the low income countries of the world. ${ }^{7}$ According to recent Word Bank report, around $24.3 \%$ of population of Pakistan is living under severe economic stress. A study has suggested, socio-economic indicators such as insufficient resources, shortage of food and debt have linear linkage with poor psychiatric health. Therefore, a study of association of psychiatric disorders with cardiovascular diseases in Pakistan can be a significant contribution to literature. In addition, if poor socioeconomic conditions are common findings in patient's history of cardiovascular disease, it could be established that poor financial condition doesn't limit to psychiatric illness but can lead to life-taking cardiovascular diseases. ${ }^{9}$

In this study, we studied the prevalence of various mental disorders in patients with cardiovascular diseases and tried to develop association between two illnesses. In addition, socioeconomic conditions are evaluated as a major risk factor behind cardiovascular diseases.

\section{Materials and Methods}

The cross sectional study was conducted at Cardiac wards from $27^{\text {th }}$ May to $27^{\text {th }}$ October 2020 at Ch.Pervaiz Elahi Institute of Cardiology Multan. Patients visiting cardiac centres were included in study after confirmation of cardiovascular diseases from the physician. Patients of age above 25 year, both male and female were included in the study. The patients were informed of the study objectives and consent was taken. Confirmed cases of cardiovascular diseases were then assessed for psychiatric disorders. Patients were evaluated for mental disorders including depression, post trauma stress disorder, anxiety, dysthymia, bipolar disorder, panic disorder with or without agoraphobia, social phobia and psychosis. Diagnosis of psychiatric illness was made in two steps: initial screening through 12item version of the General Health Questionnaire and final diagnosis was made through Psychiatrist Assessment Schedule. ${ }^{10}$ As the study was conducted in Southern Punjab where literacy rate is low; therefore, General Health Questionnaire, being brief and simple, was selected. Further, General Health Questionnaire has already established its validity in previous studies conducted in rural areas of Pakistan. The Psychiatrist Assessment Schedule, was not sufficient to identify all the disorders like psychosis. Therefore, such psychiatric illnesses were evaluated by investigating history and observing psychiatric health conditions. Interviews were conducted by trained psychiatrists with at least 5 years of experience. Apart from assessing existence of psychiatric disorders, interviewers were trained to evaluate socioeconomic conditions. Participants were interviewed for occupation, income, education and debt status. Each variable was further categorized. Occupation status was classified as skilled, unskilled and professional. Education status was subdivided into less than 10 years of education, up to 12 years and more than 16 years. Further, monthly income was divided into less than 25, 000, up to 50,000 and more than 50,000. Debt status was evaluated in terms of presence or absence.

\section{Data Analysis}

Computer software SPSS version 23 was used for data entry and analyses. Results of Psychiatric Assessment Schedule were interpreted according to the Diagnostic and Statistical Manual of Psychiatric Disorders revised version. Frequency and percentages of various mental disorders and socioeconomic condition in each category were calculated using this software. Odd ratios (OR) were used to ascertain association between mental illness (predictor) and Cardio Vascular Diseases.

\section{Results}

Total 200 patients were part of study. Out of 200, 115 (57.5\%) were male and $85(42.5 \%)$ were female. Mean age of participants was $42.7 \pm 6.7$ years. All participants were initially screened for psychological disorders. Of these 200, 94 (47\%) were diagnosed positive for psychiatric illness. 10 (10.6\%) were detected for anxiety, 20(21.2\%) for depression, 21 (22.3\%) for post trauma stress disorder, $7(7.4 \%)$ for dysthymia, 5(5.31\%) for bipolar disorder, 15 (15.9\%) for panic disorders, 6 (6.3\%) for social phobia and 10 (10.6\%) for psychosis. Table 1 indicates the statistical 
significance and association of each psychiatric illness with development of cardiovascular diseases. Theses 94 patients were then assessed for their socio-economic conditions.

\begin{tabular}{|c|c|c|}
\hline \multicolumn{3}{|c|}{$\begin{array}{l}\text { Table 1: Frequency o f Menta I Disorders a nd Their } \\
\text { Association with Cardiovascular Disease }(\mathrm{N}=200)\end{array}$} \\
\hline Mental Disorder & $\begin{array}{l}\text { Frequency N } \\
\text { (\%) }\end{array}$ & $\begin{array}{l}\text { Odd Ratio( } 95 \% \\
\text { Confidence Interval ) }\end{array}$ \\
\hline Anxiety & $10(5)$ & $0.298(0.142-0.628)$ \\
\hline Depression & $20(10)$ & $1.47(1.72-3.0)$ \\
\hline Post Trauma & $21(10.5)$ & $1.056(1.55-2.05)$ \\
\hline \multicolumn{3}{|l|}{ Stress Disorder } \\
\hline Dysthymia & $7(3.5)$ & $0.26(0.88-0.48)$ \\
\hline Bipolar Disorder & $5(2.5)$ & $0.14(0.55-0.38)$ \\
\hline Panic Phobia & $15(7.5)$ & $1.69(1.4-2.3)$ \\
\hline Social Phobia & $6(3)$ & $0.75(0.71-0.43)$ \\
\hline Psychosis & $10(5)$ & $0.36(0.17-0.78)$ \\
\hline
\end{tabular}

Among them, majority $46.8 \%$ had less than 10 years of schooling, $41.4 \%$ were having monthly income less than 25,000 per month, $42.5 \%$ were skilled, and $58.5 \%$ were indebted (Table 2 ). These results predict positive correlation of education, monthly income and debt with mental health loss which leads to cardiovascular disease.

\begin{tabular}{|c|c|}
\hline \multicolumn{2}{|c|}{$\begin{array}{l}\text { Table 2: Distribution of Study Populat } \\
\text { Income, Occupation and Debt ( } n=200)\end{array}$} \\
\hline Socio-economic determinants & Frequency $\mathrm{N}(\%)$ \\
\hline \multicolumn{2}{|l|}{ Education } \\
\hline$<10$ & $44(22)$ \\
\hline 12 & $35(17.5)$ \\
\hline $16<$ & $15(7.5)$ \\
\hline \multicolumn{2}{|l|}{ Household Income } \\
\hline$<25,000$ & 39 (19.5) \\
\hline 50,000 & $30(15)$ \\
\hline $50,000<$ & $25(12.5)$ \\
\hline \multicolumn{2}{|l|}{ Occupation } \\
\hline Skilled & $40(20)$ \\
\hline Unskilled & $32(16)$ \\
\hline Professional & $22(11)$ \\
\hline \multicolumn{2}{|l|}{ Debt } \\
\hline Present & $55(27.5)$ \\
\hline Absent & 39 (19.5) \\
\hline
\end{tabular}

\section{Discussion}

Cardiovascular diseases are growing concern around the globe. Although, several researches are conducted to ascertain the risk factors, literature still lacks the universally agreed association of various mental disorders with cardiovascular diseases. In addition, although socioeconomic challenges have been linked with mental health decline, association of all three variables, cardiovascular diseases, mental health and socioeconomic challenges, remain behind the doors. However, there is no refuting to that while high income countries are trying actively to build consensus on the subject, Pakistan has hardly come up with any such study. We, therefore, have taken the initiative to underscore the risk of challenging socioeconomic conditions and psychiatric illness in development of cardiovascular diseases.

Among the participated population, various mental disorders were seen significantly comorbid with cardiovascular disorders as concluded by Carrel et al. ${ }^{11}$ Similarly, consistent with our finding, Osborn et al conducted a cohort study of people suffering from variant psychiatric illness and found that those who suffered from life time mental disorders developed cardiovascular disease latter in their life. ${ }^{12}$ In addition , in a similar study conducted on population of United States of America, Goodwin et al found five of our evaluated psychiatric illnesses among the patients of Cardiovascular Diseases. ${ }^{13}$

Furthermore, the study tried to ascertain the risk associated with each evaluated psychiatric illness in development of cardiovascular diseases. Our results suggested that when considered individually, post trauma stress disorder, panic disorder and depression are significant risk factors for cardiovascular diseases. In compliance with our results, the significance of post trauma stress disorder is concluded in a study conducted on Danish people by Gradus et al. ${ }^{1}$ Similarly, depression is concluded as significant risk factor in causing mortality in cardiovascular disease patients. ${ }^{14}$ Although, to our knowledge, no organized data is available to validate panic disorder as a risk factor in development of cardiovascular disease; yet, Fleet at al has reviews two studies which declare panic disorder as statistically significant risk factor in cardiovascular disease development. ${ }^{15}$ Apart from the three significant psychiatric illness, other evaluated disorders when analysed individually were not found significant; however, certain cohort studies, based on longitudinal data, declared them equally significant in development of cardiovascular diseases or might even lead to mortality. ${ }^{15,16}$

We also assessed the extent of role played by 
socioeconomic conditions in causing psychiatric illness. Four indicators: education, household income, occupation and debt were used as a measure to determine socioeconomic conditions. The results showed that majority of patients with cardiovascular disorders, visited schools for less than 10 years while minority had 16 years of education. Similar results were deduced by another study where education was used as an indicator to evaluate depression in pregnant women. ${ }^{8}$ The house income as an indicator showed slightly surprising results. Although the majority among psychiatric disorders were earning $>25,000$, but this number was no significant as comparable figure was found of those who were earning $<15,000$. This concluded that income may or may not be a significant determent of psychiatric illness. Our results are, however, contrasted by the results of another study that found income as a major aggravator of psychiatric illness. ${ }^{17}$ Similarly, profession doesn't seem to be related with psychiatric health problems as almost similar figures were found of unskilled, skilled and professionals. These results were also found in contrast with major studies in literature. ${ }^{18}$ Lastly, debt burden showed positive correlation with psychiatric illness as majority among the mentally ill declared themselves indebted as concluded by Amit et al. ${ }^{19}$

However, our study has some loopholes as well. The study was case-control, conducted on a small sample size which might result in erroneous interpretation of analyses for entire population. It is recommended to conduct cohort study types with larger sample size so that further insights about the inter-relation of the variables can be gained.

\section{Conclusion}

It is concluded that majority of cardiac patients of tertiary care hospitals of Southern Punjab had a history of psychiatric illness. Post trauma stress disorder, depression and panic disorder are significantly correlated with cardiovascular diseases. Further, significant numbers of patients with comorbid mental and cardiovascular were found to have low educational status and were indebted which makes these two a risk factor in causing cardiac disorders.

\section{REFERENCE}

1. Gradus JL, Farkas DK, Svensson E, Ehrenstein V, Lash TL, Milstein A, et al. Associations between stress disorders and cardiovascular disease events in the Danish population. 2015; 5: e009334.

2. Zubair F, Nawaz SK, Nawaz A, Nangyal H, Amjad N, Khan MS. Prevalence of cardiovascular diseases in Punjab, Pakistan: a cross-sectional study. Journal of Public Health. 2018; 26: 523-9.

3. Finucane MM, Stevens GA, Cowan MJ, Danaei G, Lin JK, Paciorek $\mathrm{CJ}$, et al. National, regional, and global trends in body-mass index since 1980: systematic analysis of health examination surveys and epidemiological studies with 960 country-years and 9. 1 million participants. 2011;377: 55767.

4. Kelishadi R, Poursafa P. A Review on the Genetic, Environmental, and Lifestyle Aspects of the Early-Life Origins of Cardiovascular Disease. Current Problems in Pediatric and Adolescent Health Care. 2014; 44: 54-72.

5. Roy SS, Foraker RE, Girton RA, Mansfield AJ. Posttraumatic stress disorder and incident heart failure among a community-based sample of US veterans. American journal of public health. 2015; 105: 757-63.

6. Rajan S, McKee M, Rankarajan S, Bangdiwala S, Rosengren A, Gupta R, et al. Association of Symptoms of Depression With Cardiovascular Disease and Mortality in Low-, Middle, and High-Income Countries. JAMA Psychiatry. 2020; 77: 1052-63.

7. Razzak JA, Hyder AA, Akhtar T, Khan M, Khan UR. Assessing emergency medical care in low income countries: A pilot study from Pakistan. BMC Emergency Medicine. 2008; 8: 18.

8. Maselko J, Bates L, Bhalotra S, Gallis JA, O'Donnell K, Sikander S, et al. Socioeconomic status indicators and common mental disorders: Evidence from a study of prenatal depression in Pakistan. SSM - Population Health. 2018; 4: 1-9.

9. Khawaja IS, Westermeyer JJ, Gajwani P, Feinstein RE. Depression and Coronary Artery Disease. The Association, Mechanisms, and Therapeutic Implication. Psychiatry (Edgmont). 2009; 6: 38-51.

10. Anjara SG, Bonetto C, Van Bortel T, Brayne C. Using the GHQ12 to screen for mental health problems among primary care patients: psychometrics and practical considerations. International Journal of Mental Health Systems. 2020; 14: 1-3.

11. Carrell CU, Solmi M, Veronese N, Bortolato B, Rosson S, Santonastaso $\mathrm{P}$, et al. Prevalence, incidence and mortality from cardiovascular disease in patients with pooled and specific severe mental illness: a large-scale meta-analysis of $3,211,768$ patients and $113,383,368$ controls. World psychiatry : official journal of the World Psychiatric Association (WPA). 2017; 16: 163-80.

12. Osborn DP, Hardoon S, Omar RZ, Holt RI, King M, Larsen J, et al. Cardiovascular risk prediction models for people with severe mental illness: results from the prediction and management of cardiovascular risk in people with severe mental illnesses (PRIMROSE) research program. JAMA psychiatry. 2015; 72: 143-51. 
13. Goodwin RD, Davidson KW, Keyes KJJopr. Mental disorders and cardiovascular disease among adults in the United States. 2009; 43: 239-46.

14. Emdin CA, Odutayo A, Wong CX, Tran J, Hsiao AJ, Hunn BHM. Meta-Analysis of Anxiety as a Risk Factor for Cardiovascular Disease. The American Journal of Cardiology. 2016; 118: 511-9.

15. Fleet $\mathrm{R}$, Lavoie $\mathrm{K}$, Beitman BD. Is panic disorder associated with coronary artery disease? A critical review of the literature. Journal of Psychosomatic Research. 2000; 48: 347-56.

16. Prieto ML, McElroy SL, Hayes SN, Sutor B, Kung S, Bobo WV, et al. Association between history of psychosis and cardiovascular disease in bipolar disorder. 2015; 17: 518-27.

17. Golberstein E. The effects of income on mental health: evidence from the social security notch. J Ment Health Policy Econ. 2015; 18: 27-37.

18. Moreno Fortes A, Tian L, Huebner ES. Occupational Stress and Employees Complete Mental Health: A Cross-Cultural Empirical Study. Int J Environ Res Public Health. 2020; 17: 3629.

19. Amit N, Ismail R, Zumrah AR, Mohd Nizah MA, Tengku Muda TEA, Tat Meng EC, et al. Relationship Between Debt and Depression, Anxiety, Stress, or Suicide Ideation in Asia: A Systematic Review. Front Psychol. 2020; 11: 1336. 